\title{
DESEMPENHO EM VIVEIRO DE TRÊS ESPÉCIES FLORESTAIS NATIVAS SOB DIFERENTES AMBIENTES DE LUMINOSIDADE ${ }^{1}$
}

\author{
PERFORMANCE OF THREE NATIVE FOREST SPECIES \\ UNDER DIFFERENT LUMINOUS ENVIRONMENTS
}

\author{
Lauri Amândio Schorn², Jéssica Tainá Guczak², Maria Caroline Silva ${ }^{3}$, \\ Edier Rodrigo Andrade ${ }^{3}$, Tatiele Anete Bergamo Fenilli ${ }^{4}$, Ricardo Bittencourt ${ }^{5}$
}

\section{RESUMO}

A qualidade das mudas é um fator fundamental para alcançar o êxito na implantação de povoamentos florestais. Apesar da importância econômica e ambiental de diversas espécies florestais nativas, há necessidade de estudos sobre a produção de mudas e o comportamento silvicultural, tanto em viveiro quanto em campo. Avaliou-se o desempenho de mudas de Miconia cinnamomifolia, Matayba elaeagnoides e Luehea divaricata, quando produzidas sob diferentes níveis de luminosidade em viveiro. A pesquisa foi desenvolvida no viveiro florestal do Laboratório de Silvicultura da Universidade Regional de Blumenau. O delineamento experimental foi inteiramente casualizado. Foram estabelecidos quatro tratamentos em relação à luminosidade, assim distribuídos: Tratamento 01 (T1) com exposição a 100\% de luz; Tratamento 02 (T2), com 74\% de disponibilidade de luz; Tratamento 03 (T3) com 45\% de luminosidade; Tratamento 04 (T4), com 25\% de luminosidade. Cada tratamento foi constituído por 40 mudas, subdivididas em quatro repetições de 10 mudas em cada um deles. As avaliações das parcelas em viveiro foram realizadas mensalmente, através da mensuração das alturas e diâmetro do coleto de todas as mudas; e aos oito meses, quando foram avaliadas, as alturas, diâmetro do coleto, massa seca aérea, massa seca radicular e os teores de clorofila, utilizando-se cinco mudas de cada parcela. Também foi calculado, para cada parcela, o índice de qualidade de Dickson. Para a comparação entre os tratamentos foi realizada a análise da variância, e as médias comparadas pelo teste de Tukey, utilizando-se o nível de probabilidade de erro de 5\%. Em níveis mais baixos de luminosidade, as três espécies mostraram diminuição de incrementos e aumento nos teores de clorofila. Os níveis de luminosidade em viveiro, indicados para as espécies e nas condições do estudo são, 74\% para Miconia cinnamomifolia e Matayba elaeagnoides e $74 \%$ a $100 \%$ para Luehea divaricata.

Palavras-chave: Biomassa, Qualidade de mudas, Sistema radicular, Variáveis morfofisiológicas.

\footnotetext{
${ }^{1}$ Pesquisa desenvolvida na Universidade Regional de Blumenau através do projeto Silvicultura de Espécies Florestais Nativas

${ }^{2}$ Dr. em Ciências Florestais. Professor e Pesquisador em Silvicultura. Universidade Regional de Blumenau. Programa de Pós-Graduação em Engenharia Florestal. Rua São Paulo, 3250, Blumenau - SC. CEP 89030-080. E-mail lauri.schorn@, gmail.com

${ }^{3}$ Graduando(a) em Engenheiro Florestal. Universidade Regional de Blumenau. Rua São Paulo, 3250, Blumenau - SC.

${ }^{4}$ Dra. em Ciências (Energia Nuclear na Agricultura). Professora e Pesquisadora em Silvicultura e Conservação dos Recursos Naturais. Universidade Regional de Blumenau. Programa de Pós-Graduação em Engenharia Florestal. Rua São Paulo, 3250, Blumenau - SC. E-mail tfenilli@furb.br

${ }^{5}$ Dr. em Recursos Genéticos Vegetais. Professor e Pesquisador em Biotecnologia Vegetal. Universidade Regional de Blumenau. Programa de Pós-Graduação em Engenharia Florestal. Rua São Paulo, 3250, Blumenau - SC. E-mail ricbittencourt@furb.br
} 


\section{ABSTRACT}

The quality of seedlings is a fundamental factor to achieve success in the establishment of forest stands. Despite the economic and environmental importance of several native forest species, there is a need for studies on seedling production and silvicultural behavior in both nursery and field. The objective of this study was to evaluate the performance of seedlings of Miconia cinnamomifolia, Matayba elaeagnoides and Luehea divaricata when produced under different light levels in nursery. The research was developed in the forest nursery of the Forestry Laboratory of the Universidade Regional de Blumenau. The experimental design was completely randomized. Four treatments were established in relation to light, distributed as follows: Treatment 01 (T1) with exposure to 100\% light; Treatment 02 (T2), with 74\% light availability; Treatment 03 (T3) with 45\% luminosity; Treatment 04 (T4), with 25\% luminosity. Each treatment consisted of 40 seedlings, divided into four replications of 10 seedlings each. The evaluations of the nursery plots were carried out monthly, by measuring the height and diameter of all seedlings; and after eight months, when heights, stem diameter, aerial dry mass, root dry mass and chlorophyll contents were evaluated using five seedlings from each plot. The Dickson Quality Score was also calculated for each plot. For the comparison between the treatments, the analysis of variance was performed, and the means compared by the Tukey test, using the 5\% probability level of error. At lower levels of luminosity, the three species showed a decrease in increments and increase in chlorophyll contents. The nursery luminosity levels, indicated for the species and under the conditions of the study, are 74\% for Miconia cinnamomifolia and Matayba elaeagnoides and $74 \%$ to $100 \%$ for Luehea divaricata.

Keywords: Biomass, Morphophysiological variables, Seedling quality, Root system.

\section{INTRODUÇÃO}

O estado de Santa Catarina detém importante área de cobertura florestal nativa, embora em sua grande maioria, fragmentada e antropizada em algum nível. Apesar de alteradas, estas áreas contêm importantes reservas de material genético de diversas espécies nativas que possuem valor real ou potencial (VIBRANS et al., 2012).

Entre as espécies florestais nativas que ocorrem no Estado de Santa Catarina há um número considerável que apresenta potencial para utilização em plantios homogêneos em função de sua rusticidade, crescimento e utilização da madeira. Esse potencial já foi demonstrado por Reitz et al. (1978), que relataram no "Madeiras de Santa Catarina" as espécies nativas mais indicadas para reflorestamento no Estado. Neste sentido também é importante mencionar os resultados obtidos por Carvalho (2003) em suas publicações “Espécies Arbóreas Brasileiras”, evidenciando o potencial existente para a silvicultura de produção com a utilização de espécies nativas.

Além da restrita bibliografia relacionada às técnicas de produção de mudas de espécies nativas, as pesquisas e informações relacionadas ao desempenho de mudas em condições de campo e suas relações com a sua qualidade em viveiro são igualmente limitadas para a maioria das espécies florestais nativas. Aliado a isso, na fase de produção de mudas de qualquer espécie sempre se deve almejar um padrão de qualidade que possibilite o melhor crescimento e a maior sobrevivência no plantio em campo. 
Para essas espécies, observa-se uma demanda em relação a elaboração de protocolos completos sobre os processos de produção de mudas que incluem questões como, composição de substratos, luminosidade adequada, volumes de recipientes e fertilizações (STORCK et al., 2016). A falta ou limitado grau de conhecimento dessas metodologias compromete o uso de muitas espécies e a implantação de reflorestamentos para restauração florestal (BRANCALION; MONDO; NOVEMBRE, 2011), bem como para produção madeireira.

Nesse sentido, entre as diversas práticas culturais capazes de alterar a qualidade morfofisiológica das mudas está o nível de luminosidade a que as espécies devem ser submetidas em viveiro. A intensidade luminosa a que uma planta é submetida interfere no seu desenvolvimento ao exercer efeitos diretos sobre a fotossíntese, abertura estomática e síntese de clorofila. Conforme relatou Vidal (2008), as espécies florestais possuem desenvolvimento diferenciado em relação à luminosidade, por isso estudos a respeito do sombreamento, trazem informações importantes para a produção de mudas e uma melhor compreensão do seu papel ecológico na dinâmica de regeneração de florestas e nos plantios.

Dentre as espécies florestais nativas do sul do Brasil, Miconia cinnamomifolia (DC.) Naudin, Matayba elaeagnoides Radlk e Luehea divaricata Mart. \& Zucc., destacam-se pela qualidade de sua madeira, apresentando amplo potencial de utilização, além de projetos paisagísticos, agrossilviculturais e ambientais. No entanto, apesar de sua importância econômica e ambiental, essas espécies ainda necessitam de estudos sobre a produção de mudas e seu comportamento silvicultural, principalmente com técnicas que otimizem sua produção em viveiro, com baixo custo e adequada qualidade morfofisiológica.

Matayba elaeagnoides pertence à família Sapindaceae, é conhecida popularmente como Camboatá-branco. Lorenzi (2009) descreve a espécie como planta semidecídua, pioneira, heliófita ou esciófita e seletiva higrófita, característica de várias formações florestais fechadas ou abertas do país, apresentando vasta e expressiva dispersão. No Brasil, a espécie é encontrada nos estados de Minas Gerais, São Paulo, Mato Grosso do Sul, Paraná, Santa Catarina e Rio Grande do Sul, em diversas formações vegetacionais.

Da família Malvaceae, Luehea divaricata pode atingir 20 a $25 \mathrm{~m}$ de altura e ter diâmetro de 50 a $80 \mathrm{~cm}$ à altura do peito, com tronco geralmente tortuoso e nodoso, com base alargada e fuste de 4 a $6 \mathrm{~m}$ de comprimento, porém no interior de uma floresta densa pode formar troncos praticamente retos e maiores. É considerada espécie pioneira, de rápido crescimento, frequente nos reflorestamentos mistos em áreas degradadas dentro de Áreas de Preservação Permanente (CARVALHO, 2008; LORENZI, 2009). A espécie é decídua, heliófita e seletiva higrófita, característica das Florestas Aluviais. Apresenta dispersão irregular e descontínua, sendo particularmente frequente ao longo de rios, terrenos rochosos e íngremes. De árvores longevas, a espécie é comum na vegetação secundária, principalmente em capoeiras e invadindo pastagens (CARVALHO, 2003).

Miconia cinnamomifolia, da família Melastomataceae, ocorre de forma natural no Brasil nos estados da Bahia, Espírito Santo, Minas Gerais, Paraná, Rio de Janeiro, Santa Catarina e São Paulo. 
A espécie produz banco de sementes no solo e ocorre nas associações mais evoluídas da vegetação secundária: capoeirões e florestas secundárias situados nas encostas enxutas e íngremes, principalmente em altitudes de até $200 \mathrm{~m}$. Apresenta intensa regeneração natural e em vários estágios na Floresta Ombrófila Densa, sendo encontrada nas formações Montana e Submontana (CARVALHO, 2006). Está presente ainda na Floresta Estacional Semidecidual e ocorre também na restinga (SCHUCH et al., 2008).

Estudos com avaliação da luminosidade no desenvolvimento de mudas florestais, tem sido realizados em nível de viveiro (LIMA; ZANELLA; CASTRO, 2010; MOTA; SCALON; HEINZ, 2012; LENHARD et al., 2013; SANTOS; COELHO, 2013; SOUZA et al., 2013; SANTOS, 2016). No entanto, não foram encontrados resultados de estudos conclusivos sobre luminosidade para Miconia cinnamomifolia, Matayba elaeagnoides e Luehea divaricata.

Tendo em vista o exposto, avaliou-se o desempenho e a qualidade de mudas de Miconia cinnamomifolia, Matayba elaeagnoides e Luehea divaricata, quando submetidas a diferentes níveis de luminosidade em viveiro.

\section{MATERIAL E MÉTODOS}

A pesquisa foi desenvolvida no viveiro florestal do Laboratório de Silvicultura da Universidade Regional de Blumenau, situado no campus V da FURB no bairro Fortaleza em Blumenau - SC. O município de Blumenau está localizado ao norte de Santa Catarina e a área do experimento próximo da latitude $26^{\circ} 55^{\prime} 10^{\prime}$ " Sul e longitude $49^{\circ} 03^{\prime} 58^{\prime}$ " Oeste. A temperatura média anual é 20,1 $1^{\circ} \mathrm{C}$ e pluviosidade anual média está entre 1500 à $1600 \mathrm{~mm}$. Segundo a classificação de Koppen-Geiger, o clima de Blumenau é Cfb (clima temperado húmido com verão temperado) (PREFEITURA DE BLUMENAU, 2018).

As mudas das espécies Miconia cinnamomifolia, Matayba elaeagnoides e Luehea divaricata, utilizadas no estudo, foram produzidas no viveiro da FURB. As sementes foram provenientes de árvores situadas no município de Blumenau e colocadas para germinar logo após a sua coleta. Foram utilizados tubetes de polipropileno com $150 \mathrm{~cm}^{3}$, dispostos em bandejas plásticas. O substrato utilizado nos tubetes foi da marca Maxfertil®. O substrato Maxfertil® é formulado com casca de pinus, cinzas, vermiculita, serragem e bioestabilizados. Também estão presentes os aditivos, corretivos de acidez $(0,50 \%)$, fosfato natural $(0,50 \%)$ e fertilizante mineral N-P-K $(0,60 \%)$. O delineamento experimental utilizado foi inteiramente ao acaso com quatro tratamentos e quatro repetições por tratamento.

Os tratamentos foram caracterizados por diferentes níveis de luminosidade relativa a que as mudas foram submetidas. O Tratamento 01 (T1) continha $0 \%$ de sombreamento, ou seja, as mudas não estavam cobertas por sombrite e ficaram 100\% expostas a pleno sol. Para o Tratamento 02 (T2), a porcentagem de luz disponível foi de $74 \%$, mensurada através de luxímetro e que correspondeu a uma 
camada de sombrite. O Tratamento 03 (T3) foi composto por duas camadas sobrepostas de sombrite, equivalendo à $45 \%$ de luminosidade para as plantas. No caso do Tratamento 04 (T4), a porcentagem de luz solar foi de $25 \%$ e obtida pela sobreposição de três camadas de sombrite. O sombrite utilizado para os tratamentos é comercializado como sendo com 50\% de luminosidade e constituído de polipropileno. Para cada tratamento foram mensurados os níveis de luminosidade relativa interna dos canteiros, através de luxímetro digital KR832, coletando-se três medidas internas e três medidas externas aos tratamentos, realizando-se em seguida as respectivas médias e cálculos da luminosidade relativa.

As parcelas foram constituídas por 10 mudas para Miconia cinnamomifolia, 12 para Matayba elaeagnoides e 12 mudas para Luehea divaricata. As diferenças em número de mudas ocorreram em função da disponibilidade destas no viveiro por ocasião do início de cada experimento. As mudas de Miconia cinnamomifolia foram submetidas aos tratamentos, desde a germinação até 240 dias após, enquanto as mudas de Mataiba elaeagnoides e Luehea divaricata foram aos 30 dias após a germinação. As espécies foram semeadas em diferentes estações do ano, sendo Miconia cinnamomifolia no início do outono, enquanto Mataiba elaeagnoides e Luehea divaricata na primavera. Por esse motivo, as mudas apresentaram diferenças de idades entre as espécies no início dos experimentos.

Foram mensurados em cada muda, as variáveis, altura $(\mathrm{cm})$ e diâmetro do coleto $(\mathrm{mm})$ nas quatro primeiras avaliações, além de massa seca de raízes (g), massa seca aérea (g), mensuração de clorofilas $a$ e $b$, na última avaliação. As avaliações das mudas foram realizadas no dia da instalação do experimento e aos 30, 60, 90 e 120 dias.

Para a obtenção da massa seca, inicialmente foi realizada a separação das partes aérea e radicular de cada muda, identificando e acondicionando-as em sacos de papel. A secagem do material para a obtenção de massa seca foi realizada em estufa a $70^{\circ} \mathrm{C}$ até a obtenção de peso constante. Para tanto, foi realizada a primeira pesagem com 24 horas de secagem e as demais a cada 12 horas até não serem observadas alterações no peso em cada uma das partes das mudas (aérea e radicular), considerando-se os últimos valores como a massa seca do material.

O índice de qualidade de Dickson foi calculado para todas as parcelas de repetição do experimento, a partir da equação (DICKSON et al., 1960):

$$
\mathrm{IQD}=\frac{\mathrm{MST}(\mathrm{g})}{\left(\frac{\operatorname{ALT}(\mathrm{cm})}{\operatorname{DIAM}(\mathrm{mm})}\right)+\left(\frac{\operatorname{MSA}(\mathrm{g})}{\operatorname{MSR}(\mathrm{g})}\right)}
$$

Onde: IQD = Índice de Qualidade de Dickson; MST = Massa Seca Total (g); ALT = Altura Parte Aérea (cm); DIAM = Diâmetro do Coleto (mm); MSPA = Massa Seca Parte Área (g); MSR = Massa Seca Radicular (g).

Para a determinação dos níveis de clorofila utilizou-se o Clorofilog Falker® CFL1030. A determinação foi realizada em quatro folhas de cada planta, sendo uma em cada quadrante e situadas na porção intermediária do caule. 
Os dados obtidos nos experimentos no viveiro foram submetidos inicialmente ao teste de Shapiro-Wilk para verificar a aderência à normalidade. Para as variáveis cuja distribuição foi confirmada a tendência à normalidade, foi realizada a comparação entre os tratamentos através da análise da variância, e as médias comparadas pelo teste de Tukey, utilizando-se o nível de probabilidade de erro de 5\%. Já para as variáveis cuja distribuição não tenha apresentado aderência à distribuição normal, foi aplicado o teste de Kruskal-Wallis, utilizando-se o mesmo nível de probabilidade.

\section{RESULTADOS E DISCUSSÃO}

\section{MICONIA CINNAMOMIFOLIA}

As mudas de Miconia cinnamomifolia submetidas aos tratamentos com diferentes níveis de luminosidade apresentaram diferenças em relação ao crescimento para a maioria das variáveis analisadas. Na Tabela 1 são apresentados as médias dos tratamentos para cada variável.

Tabela 1 - Médias dos incrementos mensais das variáveis biométricas, diâmetro do colo (DC), altura (H), e médias finais de massa seca aérea (MSA), massa seca radicular (MSR), massa seca total (MST), Clorofila $a, b$,

Total e Índice de Qualidade de Dickson (IQD) das mudas de Miconia cinnamomifolia por tratamento.

\begin{tabular}{cccccccccc}
\hline $\begin{array}{c}\text { Tratamentos } \\
(\% \text { de luz) }\end{array}$ & DC (mm) & H (cm) & MAS (g) & MSR (g) & MST (g) & Clorofila a & Clorofila b & $\begin{array}{c}\text { Clorofila } \\
\text { Total }\end{array}$ & IQD \\
\hline 100 & $3,6 \mathrm{~b}$ & $17,2 \mathrm{~b}$ & $1,40 \mathrm{~b}$ & $1,51 \mathrm{~b}$ & $2,91 \mathrm{~b}$ & $19,7 \mathrm{~b}$ & $4,0 \mathrm{~b}$ & $23,7 \mathrm{c}$ & $0,52 \mathrm{~b}$ \\
\hline 74 & $4,4 \mathrm{a}$ & $23,7 \mathrm{a}$ & $2,25 \mathrm{a}$ & $2,10 \mathrm{a}$ & $4,33 \mathrm{a}$ & $21,0 \mathrm{ab}$ & $4,3 \mathrm{~b}$ & $25,3 \mathrm{bc}$ & $0,68 \mathrm{a}$ \\
\hline 45 & $4,1 \mathrm{ab}$ & $24,2 \mathrm{a}$ & $2,00 \mathrm{ab}$ & $1,46 \mathrm{~b}$ & $3,45 \mathrm{ab}$ & $25,3 \mathrm{a}$ & $5,6 \mathrm{~b}$ & $30,9 \mathrm{~b}$ & $0,47 \mathrm{~b}$ \\
\hline 25 & $3,8 \mathrm{~b}$ & $26,5 \mathrm{a}$ & $1,93 \mathrm{ab}$ & $1,16 \mathrm{~b}$ & $3,09 \mathrm{~b}$ & $29,8 \mathrm{a}$ & $8,2 \mathrm{a}$ & $38,0 \mathrm{a}$ & $0,36 \mathrm{c}$ \\
\hline
\end{tabular}

Médias seguidas de mesma letra nas colunas, não diferem significativamente entre si pelo

Teste de Tukey ao nível de 5\% de probabilidade de erro. Fonte: Construída pelos autores

Os resultados da Tabela 1 mostram que mudas Miconia cinnamomifolia apresentaram melhor desempenho sob níveis de luminosidade entre 45 a 74\% para a maioria das variáveis. Já os valores para clorofila $a, b$ e total foram significativamente superiores em menores níveis de luminosidade.

As mudas submetidas a $100 \%$ de luminosidade apresentaram os menores valores absolutos para as variáveis, com excessão da massa seca de raízes e IQD. Na avaliação da MSR, apenas o tratamento T2 trouxe diferenças significativas em relação aos demais tratamentos (Tabela 2). Como consequência, T1, T3 e T4 não apresentaram diferenças entre si. Os maiores valores de incremento da MSR para os tratamentos T2 $(2,10)$ e T1 $(1,51)$, mostram que níveis de luminosidade acima de 74\% são mais adequados para o desenvolvimento radicular das mudas de Miconia cinnamomifolia. Esse fato é confirmado pelo resultado do IQD, que apontou o melhor desempenho para mudas sob 74\% de luz, decrescendo especialmente em níveis mais baixos de luz. 
Os resultados encontrados evidenciam que a espécie tolera sombreamento parcial em seu desenvolvimento inicial, apesar de seu caráter pioneiro. Para a altura das mudas de M. cinnamomifolia, os menores níveis de luz proporcionaram os maiores valores enquanto as mudas submetidas a 100\% de luz apresentaram as menores médias. É perceptível que a exposição das mudas a pleno sol influenciou negativamente no crescimento em altura das mesmas e que a limitação da luminosidade estimulou o crescimento em altura. Esse é um comportamento esperado para espécies de caráter pioneiro e, portanto, exigentes em luz que estimulam o crescimento e a expansão foliar como mecanismo de compensação à menor luminosidade. Os teores de clorofila observados para a espécie mostraram tendência crescente com os menores níveis de luz, reforçando o comportamento da espécie de adaptação a baixos níveis de luz com o aumento dos níveis de clorofila.

\section{MATAYBA ELAEGNOIDES}

Os níveis de sombreamento a que as mudas de Matayba elaeagnoides foram submetidas, mostraram diferenças nas respostas em crescimento e desenvolvimento, para a maioria das variáveis analisadas (Tabela 2).

Tabela 2 - Médias dos incrementos mensais das variáveis biométricas, altura (H), diâmetro do coleto (DC) e médias finais de massa seca aérea (MAS), massa seca radicular (MSR), clorofila $a, b$, total e Índice de Qualidade de Dickson (IQD) de mudas de Matayba elaeagnoides, por tratamento.

\begin{tabular}{cccccccccc}
\hline $\begin{array}{c}\text { Tratamentos } \\
(\% \text { de luz) }\end{array}$ & DC (mm) & H (cm) & MSA (g) & MSR (g) & MST (g) & Clorofila a & Clorofila b & $\begin{array}{c}\text { Clorofila } \\
\text { Total }\end{array}$ & IQD \\
\hline 100 & $2,7 \mathrm{~b}$ & $13,8 \mathrm{a}$ & $0,5 \mathrm{~b}$ & $0,26 \mathrm{~b}$ & $0,76 \mathrm{c}$ & $22,3 \mathrm{~b}$ & $4,7 \mathrm{~b}$ & $27,0 \mathrm{~b}$ & $0,11 \mathrm{~b}$ \\
\hline 74 & $2,9 \mathrm{a}$ & $14,4 \mathrm{a}$ & $0,7 \mathrm{a}$ & $0,31 \mathrm{a}$ & $1,01 \mathrm{a}$ & $24,5 \mathrm{~b}$ & $5,5 \mathrm{~b}$ & $30,0 \mathrm{~b}$ & $0,14 \mathrm{a}$ \\
\hline 45 & $2,8 \mathrm{a}$ & $14,1 \mathrm{a}$ & $0,6 \mathrm{a}$ & $0,21 \mathrm{c}$ & $0,81 \mathrm{~b}$ & $32,1 \mathrm{~b}$ & $8,7 \mathrm{~b}$ & $40,9 \mathrm{~b}$ & $0,10 \mathrm{~b}$ \\
\hline 25 & $2,4 \mathrm{c}$ & $11,9 \mathrm{~b}$ & $0,4 \mathrm{c}$ & $0,16 \mathrm{~d}$ & $0,56 \mathrm{~d}$ & $37,3 \mathrm{a}$ & $12,3 \mathrm{a}$ & $49,6 \mathrm{a}$ & $0,08 \mathrm{c}$ \\
\hline
\end{tabular}

Médias seguidas de mesma letra nas colunas, não diferem significativamente entre si pelo

Teste de Tukey ao nível de 5\% de probabilidade de erro. Fonte: Construída pelos autores

As mudas de Matayba elaeagnoides apresentaram incrementos superiores em DC sob níveis de luminosidade entre 45 a 74\%. Já o desenvolvimento em altura não mostrou diferenças significativas entre 45 a $100 \%$ de luz. Para essas duas variáveis as mudas apresentaram o pior desempenho com $25 \%$ de luz.

Para as variáveis massa seca, aérea, radicular e total, a luminosidade ao nível de $74 \%$ foi a mais adequada, enquanto o pior desempenho das mudas foi observado no menor nível de luz. O mesmo comportamento foi observado para a espécie em relação ao IQD, evidenciando que o nível de 74\% de luz foi o mais adequado para a espécie.

Os teores de clorofila $a$, $b$ e total, evidenciaram que no menor nível de luz estudado, os valores foram significativamente superiores em relação aos demais tratamentos. 


\section{LUEHEA DIVARICATA}

Conforme apresentado na Tabela 3, todas as variáveis analisadas das mudas de Luehea divaricata apresentaram diferença estatística em pelo menos um tratamento.

Tabela 3 - Médias dos incrementos mensais das variáveis biométricas, diâmetro do coleto (DC), altura (H) e médias finais de massa seca aérea (MAS), massa seca radicular (MSR), massa seca total (MST), clorofilas $a, b$, total e Índice de Qualidade de Dickson (IQD), de mudas de Luehea divaricata, por tratamento.

\begin{tabular}{cccccccccc}
\hline $\begin{array}{c}\text { Tratamentos } \\
(\% \text { de luz) }\end{array}$ & $\begin{array}{c}\text { DC } \\
(\mathbf{m m})\end{array}$ & H (cm) & MSA (g) & MSR (g) & MST (g) & Clorofila a & Clorofila b & $\begin{array}{c}\text { Clorofila } \\
\text { Total }\end{array}$ & IQD \\
\hline 100 & $1,2 \mathrm{a}$ & $7,1 \mathrm{~b}$ & $2,02 \mathrm{ab}$ & $2,21 \mathrm{a}$ & $4,23 \mathrm{a}$ & $20,8 \mathrm{~b}$ & $4,8 \mathrm{~b}$ & $25,6 \mathrm{~b}$ & $0,60 \mathrm{a}$ \\
\hline 74 & $1,1 \mathrm{a}$ & $7,5 \mathrm{~b}$ & $2,27 \mathrm{a}$ & $2,16 \mathrm{a}$ & $4,43 \mathrm{a}$ & $22,1 \mathrm{~b}$ & $5,1 \mathrm{~b}$ & $27,2 \mathrm{~b}$ & $0,59 \mathrm{a}$ \\
45 & $1,2 \mathrm{a}$ & $8,8 \mathrm{a}$ & $2,57 \mathrm{a}$ & $1,84 \mathrm{a}$ & $4,41 \mathrm{a}$ & $29,7 \mathrm{a}$ & $8,8 \mathrm{a}$ & $38,5 \mathrm{a}$ & $0,47 \mathrm{~b}$ \\
\hline 25 & $1,0 \mathrm{~b}$ & $9,1 \mathrm{a}$ & $1,05 \mathrm{~b}$ & $1,05 \mathrm{~b}$ & $2,10 \mathrm{~b}$ & $31,5 \mathrm{a}$ & $9,6 \mathrm{a}$ & $41,1 \mathrm{a}$ & $0,21 \mathrm{c}$ \\
\hline
\end{tabular}

Médias seguidas de mesma letra nas colunas, não diferem significativamente entre si pelo

Teste de Tukey ao nível de 5\% de probabilidade de erro. Fonte: Construída pelos autores

As mudas de Luehea divaricata mostraram melhores incrementos em DC quando submetidos a níveis mais elevados de luz, não havendo, no entanto, diferenças significativas entre 45 a $100 \%$ de luminosidade. Como consequência, o menor incremento médio em DC foi obtido com $25 \%$ de luz.

No entanto, os incrementos médios em altura das mudas mostraram resultados diferentes pois, maiores incrementos foram obtidos em menores níveis de luz, mais precisamente entre 25 a $45 \%$. Este comportamento não difere do que foi apresentado por Miconia cinnamomifolia, confirmando que menores níveis de luz estimulam o crescimento em altura e a expansão de área foliar das mudas como forma de compensação para atingir suficiente capacidade fotossintética.

Na produção de massa seca, Luehea divaricata apresentou teores mais elevados e não diferentes significativamente entre 45 a 100\% de luminosidade, indicando pouca tolerância ao sombreamento.

As respostas das mudas quanto aos teores de clorofila mostraram comportamentos semelhantes para as três espécies em estudo. Nas Tabelas 1, 2 e 3 observa-se claramente a tendência de maior acúmulo de clorofila $a$, $b$ e total, quando submetidas aos menores níveis de luminosidade. Já o índice de qualidade de Dickson mostrou que em maiores níveis de luz, entre 74 a 100\%, as mudas apresentaram melhor desempenho.

Os resultados apresentados por Miconia cinnamomifoia e Matayba elaeagnoides apontaram que o sombreamento parcial das mudas resultou em melhor desempenho das mesmas no incremento em DC, enquanto Luehea divaricata mostrou resultados indiferentes até o nível de 45\% de luz. Observa-se que o nível de tolerância à sombra é característica distinta entre espécies, conforme demonstrado neste e em outros trabalhos. Pode-se citar os resultados encontrados por Melo e Cunha (2009), que obtiveram os melhores resultados de médias para o DC de Erythrina mulungu, quando submetido a níveis de $20 \%$ a $60 \%$ de sombreamento. 
Muitos autores relacionam maiores valores em diâmetros com maior intensidade de luz e que indivíduos com maiores valores de diâmetro de coleto indicam melhores taxas de sobrevivência no campo (MARANA, MIGLIORANZA, FONSECA, 2015). No presente estudo, mesmo sendo espécie com comportamento pioneiro, Miconia cinnamomifolia mostrou melhor desempenho no desenvolvimento em DC em nível de luminosidade inferior a 100\%. Outros estudos têm apontado que essa variável é a que melhor representa o desempenho no pós-plantio, indicando a qualidade das mudas, porém ocorrendo variações para cada espécie e condições de plantio (RITCHIE; LANDIS; DUMROESE, 2010; AIMI, 2016).

Em relação ao crescimento em altura, as respostas das espécies estudadas também foram distintas. Miconia cinnamomifolia e Luehea divaricata apresentaram maiores incrementos em altura em menores níveis de luz, enquanto Matayba elaeagnoides mostrou respostas indiferentes em altura até o nível mínimo de $45 \%$ de intensidade luminosa. Outros autores como Santos e Coelho (2014), observaram também em indivíduos de Ochroma pyramidale que os maiores valores encontrados para altura de planta foram obtidos no ambiente com $50 \%$ de luz. Santos (2016), em estudo realizado com Luehea divaricata, obteve melhores resultados em incrementos em altura com até $30 \%$ de sombreamento e em diâmetro do coleto com níveis de luz ente 70 a 100\%. A mesma autora encontrou resultados distintos para Myrocarpus frondosus, espécie em que houve maior desenvolvimento em altura e em DC em níveis mais elevados de sombreamento. Os resultados confirmam que, para algumas espécies, a capacidade de crescerem rapidamente em locais sombreados é um fator importante para adaptação ao ambiente, e se trata de uma importante estratégia para fuga ao baixo nível de intensidade luminosa.

No entanto, a altura é considerada como um dos parâmetros mais antigos na classificação e seleção de mudas, podendo ser indicada como um parâmetro para essa avaliação, porém devem-se considerar outros fatores (GOMES; PAIVA, 2011). Desta forma, a variável altura, quando utilizada isoladamente, pode não representar o real potencial das mudas.

Fato semelhante foi observado no presente trabalho em relação à massa seca aérea, pois as mudas submetidas a plena luz obtiveram menores teores de MSA. O acúmulo de massa seca foliar em tratamentos com menores níveis de luz pode ter ocorrido devido a uma compensação à menor quantidade de radiação disponível, fato já constatado em outros trabalhos, como é o caso de Gonçalves et al. (2012). Estes autores realizaram um estudo com Swietenia macrophylla King e demonstraram que a espécie apresenta plasticidade fisiológica sob altas ou baixas irradiâncias, resultados próximos aos da presente pesquisa, onde as plantas cultivadas nos níveis de 70\% e 50\% de luminosidade apresentaram maiores valores de massa seca nas folhas quando comparada as plantas que cresceram em pleno sol. Neste sentido, Gazolla-Neto et al. (2013) ao estudar o comportamento de Solanum americanum Mill. em diferentes ambientes de luminosidade obtiveram resultados distintos para as variáveis analisadas, evidenciando a plasticidade da espécie em relação à luminosidade. 
Em relação a isso, cabe destacar a observação de Andrade (2010) de que a matéria seca acumulada pelas plantas, deve-se em média, $90 \%$ à atividade fotossintética, a qual pode ser afetada pela radiação disponível, e as demais atividades estão relacionadas à disponibilidade de nutrientes do solo.

Outros autores (GOMES; PAIVA, 2011; ARAÚJO et al., 2018) observaram que a MSA indica a rusticidade das mudas e, portanto, para as espécies avaliadas no presente estudo, níveis intermediários de luminosidade podem ser utilizados na fase de viveiro. Em estudos semelhantes com Himenaea courbaril e com Enterologium timbuava realizados por Lima et al. (2010), estes autores concluíram que as duas espécies apresentaram o pior desempenho para a maioria das variáveis analisadas, quando as mudas foram submetidas a $100 \%$ de luminosidade.

No presente trabalho, o desenvolvimento da massa seca de raízes mostrou tendência diferente da MSA. O desenvolvimento radicular de mudas apresenta relação com a acumulação de reservas e, consequentemente, com o crescimento inicial após o plantio em campo (ARAUJO et al., 2018). Ao mesmo tempo, a MSR pode apresentar relação com o DC, conforme resultados apontados por Aimi et al. (2016) em que mudas de Cabralea canjerana prontas para expedição do viveiro demonstraram alta correlação $(0,91)$ entre DC e a matéria seca radicular, enquanto outras como Handroanthus heptaphyllus indicaram baixa correlação $(0,55)$ (TONETTO, 2014).

Desta forma, a produção de mudas em níveis adequados de luz em viveiro contribui para o melhor crescimento inicial em campo. Em Miconia cinnamomifolia, os maiores valores de MSR foram encontrados em mudas submetidas a 74\% de luz, ocorrendo o mesmo para Matayba elaeagnoides, enquanto para Luehea divaricata não houve diferenças significativas do incremento em MSR entre 45 a 100\% de luz. Portanto, em ambientes com sombreamento também pode ocorrer acúmulo de MSR. Desta forma, muitas espécies não estão adaptadas para crescer normalmente em ambientes muito sombreados, reduzindo o acúmulo de massa seca com baixos níveis de luminosidade (TAIZ; ZAGER, 2013; RORATO et al., 2018), como é o caso das três espécies do presente estudo, que apresentaram os menores valores em acúmulo de massa seca aérea, radicular e total. Por outro lado, as três espécies em estudo não apresentaram o melhor desempenho quando submetidas ao ambiente com 100\% de luminosidade, resultado reforçado pelos valores do IQD, evidenciando que níveis intermediários de luz são mais indicados para estas espécies, na fase de viveiro. Resultado convergente foi obtido por Aimi (2016), que estudou o desempenho de Cabralea canjerana em diferentes ambientes de luminosidade em campo e concluiu que em intensidade de luz próximo de 50\% foi o ambiente mais adequado para a espécie. Em trabalho semelhante e com a mesma espécie, Felippi (2010) também observou que a pleno sol a sobrevivência foi baixa e em área de sub-bosque, com sombreamento de $50 \%$ esse índice de sobrevivência foi superior a $80 \%$.

Os resultados obtidos para os teores de clorofila nas mudas e sua relação com os níveis de luz, reforçam a capacidade de adaptação a menores níveis de luz e consequente sobrevivência nesses ambientes, que algumas espécies apresentam. Sobre esse aspecto, Santos (2016) comenta que a intensidade 
luminosa pode ocasionar alterações nas plantas, onde em intensidades elevadas de luz as moléculas de clorofila são passíveis de processos de foto-oxidação. Já as plantas em desenvolvimento sob baixas intensidades luminosas apresentam maiores teores de clorofila por unidade de massa, ocorrendo um aumento na capacidade fotossintética por unidade de área, pelo aumento do número de cloroplastos e de enzimas fotossintéticas. Assim, plantas em ambientes com baixa luminosidade apresentam maior grau de esverdeamento das folhas, o que se deve à maior taxa de pigmentos clorofilados por unidade de área.

As clorofilas $a$ e $b$ absorvem a luz em dois picos na região do azul (400 a $500 \mathrm{~nm}$ ) e do vermelho (600 a $700 \mathrm{~nm}$ ), respectivamente. O aumento da proporção de clorofila $b$ é uma característica importante de ambientes sombreados, porque esta capta energia de outros comprimentos de onda e a transfere para a clorofila $a$ que efetivamente atua nas reações fotoquímicas da fotossíntese e representa um mecanismo de adaptação à condição de menor intensidade luminosa (TAIZ; ZEIGER, 2013). As três espécies estudadas apresentaram maiores valores para os teores de clorofila em menores intensidades de luz, evidenciando que apresentam mecanismo de adaptação a níveis de radiação mais baixos e, desta forma, toleram sombreamento parcial em viveiro. O resultado é convergente com o que foi obtido por Lima et al. (2010) com as espécies Himenaea courbaril e Enterologium timbuava, onde o acréscimo do nível do sombreamento provocou uma menor relação clorofila $a / b$ e aumento nas concentrações de clorofila total.

Os resultados obtidos neste e em outros trabalhos sobre o desempenho de plantas em ambientes de luz permitem ratificar o que foi relatada por Gazolla-Neto et al. (2013). Para esses autores, a eficiência do crescimento pode estar relacionada à habilidade de adaptação das plantas às condições luminosas do ambiente, sendo o crescimento satisfatório de algumas espécies em ambientes com baixa ou alta luminosidade atribuído à capacidade da espécie ajustar rapidamente seu modelo de alocação de biomassa e comportamento fisiológico.

\section{CONCLUSÕES}

As três espécies em estudo mostraram diminuição de incrementos em níveis muito baixos de luminosidade, para a maioria das variáveis analisadas.

Mudas de Miconia cinnamomifolia e de Matayba elaeagnoides toleram sombreamento parcial em viveiro, pois apresentaram maiores incrementos mensais em altura, diâmetro do coleto, massa seca aérea, massa seca radicular e total, sob luminosidade entre 45 a $74 \%$.

Mudas de Luehea divaricata mostraram maior tolerância ao sombreamento, pois tiveram redução significativa de crescimento somente ao nível de $25 \%$ de luminosidade.

Em menores níveis de luminosidade as três espécies apresentaram aumentos nos teores de clorofila, comportamento caracterizado como uma estratégia para sobrevivência sob baixos níveis de luz.

Os níveis de luminosidade em viveiro, indicados para as espécies e nas condições do estudo são, 74\% para Miconia cinnamomifolia e Matayba elaeagnoides e 74 a 100\% para Luehea divaricata. 


\section{REFERÊNCIAS}

AIMI, S. C. et al. Volumen de contenedores y dosis de fertilizante de liberación controlada en el crecimiento de plantas de Cabralea canjerana producidas en vivero. Bosque, Valdivia, v. 37, n. 2, p. 401-407, 2016.

AIMI, S. C. Tecnología de sementes e crescimento inicial de mudas de Cabralea canjerana (Vell.)

Mart. 2016. 80 f. Dissertação (Mestrado) - Departamento de Engenharia Florestal, Universidade Federal de Santa Maria. Santa Maria, 2016.

ANDRADE, R.; CAVALCANTE, S.; SANTOS, J.; SILVA, M.; LIMA, S.; PAIVA, R. Caracterização da radiação solar acumulada no crescimento vegetativo do algodoeiro colorido BRS Rubi submetidas a diferentes lâminas de irrigação. In: IV CONGRESSO BRASILEIRO DE MAMONA E I SIMPÓSIO INTERNACIONAL DE OLEAGINOSAS ENERGÉTICAS. 2010, João Pessoa. Anais... João Pessoa: Embrapa Algodão, 2010, 1197 p. v. 1

ARAÚJO, M. M.; NAVROSKI, M. C.; SCHORN, L. A.; TABALDI, L. A.; RORATO, D. G.; TURCHETTO, F.; ZAVISTANOVICZ, T. C.; BERGHETTI, A. L. P.; AIMI, S. C.; TONETTO, T. da S.; GASPARIN, E.; DUTRA, A. F.; MEZZOMO, J. C.; GOMES, D. R.; GRIEBELER, A. M.; SILVA, M. R. da; BARBOSA, F. M.; LIMA, M. S. de. Caracterização e análise de atributos morfológicos e fisiológicos indicadores da qualidade de mudas em viveiro florestal. In: ARAÚJO, M. M.; NAVROSKI, M.; SCHORN, L. A. (Ed.). Produção de sementes e mudas: um enfoque à silvicultura. Santa Maria: Editora UFSM, 2018. p. 345-382.

BRANCALION, P. H. S.; MONDO, V. H. V.; NOVEMBRE, A. D. da L. C. Escarificação química para a superação da dormência de sementes de saguaraji-vermelho (Colubrina glandulosa Perk. Rhamnaceae). Rev. Árvore [online], Viçosa, v. 35, n.1, p. 119-124, 2011.

CARVALHO, P. E. R. Espécies arbóreas brasileiras. Colombo: Embrapa Florestas, 1039 p. 2003

CARVALHO, P. E. R. Jacatirão-Açu (Miconia cinnamomifolia). Circular técnica. Colombo: Embrapa Florestas p. 1-9. 2006.

CARVAlHO, P. E. R. Açoita-Cavalo (Luehea divaricata). Circular técnica. Colombo: Embrapa Florestas p. 2-48. 2008. 
DICKSON, A.; LEAF, A.L.; HOSNER, J.F. Quality appraisal of white spruce and white pine seedling stock in nurseries. Forest Chronicle, v. 36, p.10-13, 1960. Disponível em: https://bit.ly/3dg525s. Acesso em 23 maio 2018.

FELIPPI, M. Morfologia e silvicultura de espécies arbóreas da Floresta Estacional Decidual. 2010. 211 f. Tese (Doutorado em Engenharia Florestal) - Universidade Federal de Santa Maria, Santa Maria, 2010.

GAZOLLA-NETO, F.; AUMONDE, T. Z.; PEDÓ, T.; OLSEN, D.; VILLELA, F. A. Ação de níveis de luminosidade sobre o crescimento de plantas de maria-pretinha (Solanum americanum Mill.). Revista Brasileira de Biociências, Porto Alegre, v. 11, n. 1, p. 88-92, jan./mar. 2013

GONÇAlVES, J. F. de C.; SILVA, C. M. da; JUSTINO, G. C.; NINA JUNIOR, A. da R. Efeito do ambiente de luz no crescimento de plantas jovens de mogno (Swietenia macrophylla King). Scientia Forestalis. Piracicaba, v. 40, n. 95, p. 337-344, set. 2012

LENHARD, N. R. et al. Crescimento de mudas de pau-ferro sob diferentes níveis de sombreamento. Pesquisa Agropecuária Tropical, Goiânia, v. 43, n. 2, p. 178-186, 2013.

LIMA, A. L. D. S., ZANELLA, F. \& CASTRO, L. D. M. D. Growth of Hymenaea courbaril L. var. stilbocarpa (Hayne) Lee et Lang. and Enterolobium contortisiliquum (Vell.) Morong (Leguminosae) under different shading levels. Acta Amazonica, Manaus, v. 40, p. 43-48, 2010

LORENZI, H. Árvores brasileiras :manual de identificação e cultivo de plantas arbóreas nativas do Brasil. Nova Odessa: Plantarum, 2009, v. 3, 385 p.

MARANA, J. P.; MIGLIORANZA, E.; FONSECA, E. de P. Qualidade de mudas de jaracatiá submetidas a diferentes períodos de sombreamento em viveiro. Revista Árvore, Viçosa, v. 39, n. 2 , p. $275-282,2015$

MELO, R. R.; CUNHA, M. do C. L. Crescimento inicial de mudas de mulungu (Erythrina velutina Wild.) sob diferentes níveis de luminosidade. Initial growth of Erythrina velutina Wild. Changes under different luminosity levels. Ambiência, Guarapuava, v. 4, n. 1, p. 67-77, 2009

MOTA, L. H. S.; SCALON, S. P. Q.; HEINZ, R. Sombreamento na emergência de plântulas e no crescimento inicial de Dipteryx alata Vog. Ciência Florestal, Santa Maria, v. 22, n. 3, p. 423-431, 2012. 
PREFEITURADE BLUMENAU. Dados Geográficos. Blumenau, 2018. Disponível em: https://bit.ly/ 2W91FKD. Acesso em: 15 de Fevereiro 2018.

REITZ, R.; KLEIN, R. M.; REIS, A. Projeto Madeira de Santa Catarina. Itajaí: Herbário Barbosa Rodrigues, 1978.320 p.

RITCHIE, G. A.; LANDIS, T. D.; DUMROESE, R. K. et al. Assessing plant quality. Seedling Processing, Storage, and Outplanting. Washington, DC: U.S. Department of Agriculture Forest Service v. 7, 2010, 200 p.

RORATO, D. G.; ARAUJO, M. M..; TABALDI, L A.; TURCHETTO, F.; BERGHETTI, A. L. P.; BRIEBELER, A. M.; BARBOSA, F. M.; AIMI, S. C. Sobrevivência e crescimento inicial de mudas de espécies florestais nativas: experiências com plantios em áreas ripárias no sul do Brasil. In: Produção de sementes e mudas. Um enfoque à Silvicultura. ARAUJO, M. M.; NAVROSKI, M.; SCHORN, L. A. (Org). Santa Maria: Editora UFSM, 2018.

SANTOS, A. Crescimento e fisiologia de mudas de Myrocarpus frondosus Allem. (Fabaceae) e Luehea divaricata Mart. \& Zucc. (Malvaceae) sob diferentes níveis de sombreamento. 2016, $80 \mathrm{f}$. Dissertação (Mestrado) - Departamento de Engenharia Florestal, Universidade Federal de Santa Maria, Santa Maria, 2016.

SANTOS, L. W.; COELHO, M. de F. B. Sombreamento e substratos na produção de mudas de Erythrina velutina Willd., Ciência Florestal, Santa Maria, v. 23, n. 4, out.-dez., 2014.

SCHUCH, C.; SIMINSKI, A.; FANTINI, A. C. Usos e potencial madeireiro do jacatirão-açu (Miconia cinnamomifolia (DE CANDOLLE) NAUDIN) no litoral de Santa Catarina. Floresta, Curitiba, v. 38, n. 4, p. 735-741, out./dez. 2008.

SOUZA, A. S.; DE ABREU, S. D. C.; DA SILVA, C. M.; DOS SANTOS, J. X.; REIS, A. R. S. Desenvolvimento inicial de plântulas de tamboril Enterolobium contortisiliquum (Vell.) Morong em diferentes níveis de intensidade luminosa. Informativo Abrates. Londrina, v. 23, n. 3, 2013.

STORCK, E. B.; SCHORN, L. A.; FENILLI, T. A. B. Crescimento e Qualidade de mudas de Eucalyptus urophylla x Eucalyptus grandis em diferentes recipientes. Floresta. Curitiba: v. 46, n. 1, p. 39-46, jan./mar. 2016. 
TAIZ, L.; ZEIGER, E. Fisiologia vegetal. Porto Alegre: Artmed, 2013. 918 p.

TONETTO, T. da S. Tecnologia de sementes e desenvolvimento de mudas de Handroanthus heptaphyllus (Mart.) Mattos sob diferentes formas de manejo no viveiro e no campo. 2014. $137 \mathrm{f}$. Dissertação (Mestrado em Engenharia Florestal) - Universidade Federal de Santa Maria, Santa Maria, 2014.

VIBRANS, A.C.; SEVEGNANI, L.; GASPER, A.L.; LINGNER, D.V. Inventário Florístico Florestal de Santa Catarina. Diversidade e Conservação dos Remanescentes Florestais. Blumenau: Edifurb, 2012,344 p.

VIDAL, C. Y. Transplante de plântulas e plantas jovens como estratégia de produção de mudas para a restauração de áreas degradadas. 2008, 171 f. Dissertação (Mestrado em Recursos Florestais) Escola Superior de Agricultura Luiz de Queiros, Universidade de São Paulo, Piracicaba, 2008. 
